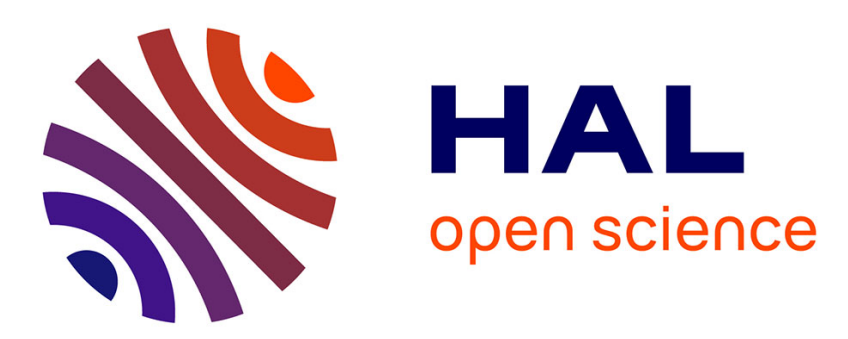

\title{
Contribution of individual musculo-tendon forces to the axial compression force of the femur during normal gait
}

Florent Moissenet, Laurence Cheze, Raphaël Dumas

\section{To cite this version:}

Florent Moissenet, Laurence Cheze, Raphaël Dumas. Contribution of individual musculo-tendon forces to the axial compression force of the femur during normal gait. Movement \& Sport Sciences - Science \& Motricité, 2016, 93, pp.63-69. 10.1051/sm/2015041 . hal-01309187v2

\section{HAL Id: hal-01309187 \\ https://hal.science/hal-01309187v2}

Submitted on 21 Apr 2017

HAL is a multi-disciplinary open access archive for the deposit and dissemination of scientific research documents, whether they are published or not. The documents may come from teaching and research institutions in France or abroad, or from public or private research centers.
L'archive ouverte pluridisciplinaire HAL, est destinée au dépôt et à la diffusion de documents scientifiques de niveau recherche, publiés ou non, émanant des établissements d'enseignement et de recherche français ou étrangers, des laboratoires publics ou privés. 


\title{
Contribution of individual musculo-tendon forces to the axial compression force of the femur during normal gait ${ }^{\star}$
}

\author{
Florent Moissenet ${ }^{1}$, Laurence Chèze ${ }^{2,3,4}$ and Raphaël Dumas ${ }^{2,3,4}$ \\ 1 CNRFR - Rehazenter, Laboratoire d'Analyse du Mouvement et de la Posture, 1 rue André Vésale, L-2674 Luxembourg, \\ Luxembourg \\ 2 Université de Lyon, F-69622, Lyon, France \\ 3 Université Claude Bernard Lyon 1, Villeurbanne, France \\ 4 IFSTTAR, UMR T9406, LBMC Laboratoire de Biomécanique et Mécanique des Chocs, F-69675, Bron, France
}

Received 6 March 2015 - Accepted 30 September 2015

\begin{abstract}
Recent musculoskeletal models allow the investigation of the contribution of individual musculo-tendon forces to the locomotion dynamics. However, most of the studies are based on a forward dynamics with a high computational cost and have principally investigated the contribution to the ground reaction forces and the centre of mass acceleration. The aim of this study was to apply a pseudo-inverse method to a musculoskeletal model that includes the contact, ligament and bone forces. The results replicated well the literature for the contributions of individual musculotendon forces to both the vertical ground reaction force and the total tibiofemoral contact force, and provide new insights for the axial compression force of the femur during normal gait.
\end{abstract}

Key words: Contribution, interaction, static optimisation, musculo-tendon forces, musculoskeletal modelling

Résumé. Contribution des forces musculo-tendineuses individuelles à la force de compression axiale du fémur pendant la marche.

Les modèles musculo-squelettiques récents permettent d'estimer la contribution des forces musculotendineuses à la dynamique de locomotion. Cependant, la plupart des études utilisent une formulation en dynamique directe avec des temps de calculs importants et se focalisent principalement sur la contribution aux forces de réaction au sol ou à l'accélération du centre de masse. L'objectif de cette étude était d'appliquer une méthode basée sur une pseudo-inverse à un modèle musculosquelettique incluant les forces articulaires, ligamentaires et osseuses. Les résultats reproduisent bien la littérature pour la contribution des forces musculo-tendineuses à la force de réaction au sol et à la force de contact tibiofémorale et donnent un nouvel éclairage pour la force de compression du fémur pendant la marche.

Mots clés : Contribution, interaction, optimisation statique, forces musculo-tendineuses, modélisation musculo-squelettique

\section{Introduction}

During a movement, the structures composing the musculoskeletal system (i.e., muscles, tendons, ligaments, contact surfaces, bones) interact each other (Pandy \& Andriacchi, 2010). In this sense, muscles have been

\footnotetext{
* Ce travail a fait l'objet d'une présentation orale lors du congrès de la SOFAMEA (Société francophone d'analyse du mouvement chez l'enfant et l'adulte) du 4 au 6 février 2015 à Genève.
}

described as the primary contributors to joint loading (Herzog, Longino, \& Clark, 2003) and recent in vivo measurements have shown that these loadings can reach 1.5 times the body weight during gait in the compartments of the tibiofemoral joint (Kim et al., 2009). Consequently, study of the contribution of individual musculotendon forces may allow a better comprehension of the underlying mechanisms during gait (Pandy \& Andriacchi, 2010) and may provide insight about either pathologic gait patterns (Higginson, Zajac, Neptune, Kautz, \& Delp, 2006; Steele, Seth, Hicks, Schwartz, \& Delp, 
2013) or the progression of joint disorders such as osteoarthritis (Herzog et al., 2003; Sasaki \& Neptune, 2010; Shelburne, Torry, \& Pandy, 2006). However, measuring individual musculo-tendon forces, and their contribution to surroundings structures, remains invasive and so almost impractical. To overcome this limitation, musculoskeletal models have been promoted these last two decades (Chèze, Moissenet, \& Dumas, (In press); Erdemir, McLean, Herzog, \& van den Bogert, 2007; Pandy \& Andriacchi, 2010). Even if these models remain most of the time generic and partially validated, they provide a unique framework for investigating musculotendon and osteo-articular forces during a movement. In this way, several studies have analysed the contributions of individual musculo-tendon forces to ground reaction forces (Anderson \& Pandy, 2003; Lin, Kim, \& Pandy, 2011; Neptune, Zajac, \& Kautz, 2004; Pandy \& Andriacchi, 2010), acceleration of the centre of mass (Correa \& Pandy, 2013; Hamner \& Delp, 2013; Jansen, De Groote, Duysens, \& Jonkers, 2013; Liu, Anderson, Schwartz, \& Delp, 2008; Steele et al., 2013), angular accelerations of joints (Arnold, Schwartz, Thelen, \& Delp, 2007; Goldberg \& Kepple, 2009) or linear and angular accelerations of segments (Barrett, Besier, \& Lloyd, 2007; Fox \& Delp, 2010; Klemetti, Steele, Moilanen, Avela, \& Timonen, 2014; Neptune et al., 2004), abduction/adduction moment at the knee (Pandy \& Andriacchi, 2010; Shelburne et al., 2006; Sritharan, Lin, \& Pandy, 2012). However, fewer studies have analysed the contributions of individual musculo-tendon forces to hip joint contact forces (Correa, Crossley, Kim, \& Pandy, 2010; Pandy \& Andriacchi, 2010), tibiofemoral joint contact forces (Collins \& O'Connor, 1991; Fregly et al., 2009; Sasaki \& Neptune, 2010; Shelburne et al., 2006; Sritharan et al., 2012; Winby, Lloyd, Besier, \& Kirk, 2009) and ankle joint contact forces (Pandy \& Andriacchi, 2010) and, to the authors' knowledge, no study has analysed the contributions of individual musculo-tendon forces to patellofemoral forces, to ligament forces or to bone forces. Moreover, most of the studies are based on a forward dynamics approach (Anderson \& Pandy, 2003; Arnold et al., 2007; Correa et al., 2010; Fox \& Delp, 2010; Jansen et al., 2013; Klemetti et al., 2014; Liu et al., 2008; Neptune et al., 2004; Pandy \& Andriacchi, 2010; Sasaki \& Neptune, 2010; Steele et al., 2013) with a high computational cost and the introduction of complex models such as foot to ground contact models (Pandy \& Andriacchi, 2010).

The aim of this study was thus to apply an alternative method using an inverse dynamics approach based on the use of a pseudo-inverse (Lin et al., 2011) to a recent 3D lower limb musculoskeletal model (Moissenet, Chèze, \& Dumas, 2014) allowing the investigation of the contributions of individual musculo-tendon forces to all the forces of the osteo-articular system that may appear in the inverse dynamics formulation. The estimated contributions of individual musculo-tendon forces to ground reaction forces and tibiofemoral contact forces were compared to the literature (Lin et al., 2011; Sritharan et al., 2012). Then, the current knowledge on the interactions between the structures composing the musculoskeletal system was extended by providing the contribution of individual musculo-tendon forces to the axial compression force of the femur during normal gait.

\section{Method}

\subsection{Musculoskeletal model}

A previously described (Moissenet et al., 2014) 3D lower limb musculoskeletal model, consisting of pelvis, thigh, patella, shank and foot segments and 43 muscular lines of action was used to perform this study. Hip, tibiofemoral, patellofemoral and ankle joint kinematic models were all based on anatomical considerations. Hip joint was modelled by a spherical joint. Tibiofemoral joint was modelled by a parallel mechanism made of two sphereon-plane contacts (i.e., medial and lateral) and three isometric ligaments (i.e., anterior cruciate ligament - ACL, posterior cruciate ligament - PCL and medial collateral ligament - MCL) (Feikes, O'Connor, \& Zavatsky, 2003). Patellofemoral joint was modelled by a hinge joint between the patella and the femur and an isometric ligament (i.e., the patellar tendon - PT) between the patella and the tibia (Sancisi \& Parenti-Castelli, 2011). Ankle joint was modelled by a parallel mechanism made of a spherical joint and two isometric ligaments (between tibia and calcaneus - TiCaL and between fibula and calcaneus - CaFiL) (Di Gregorio, Parenti-Castelli, O'Connor, \& Leardini, 2007). Based on these models, joint kinematics was estimated through a multibody optimisation that minimises, under rigid body and kinematic constraints, the sum of squared distances between measured and model-determined skin markers positions (Duprey, Cheze, \& Dumas, 2010). Then, in order to compute muscular lever arms, a widely-used generic musculoskeletal geometric model (Delp et al., 1990) complete this model. For details relating to the model, see (Moissenet et al., 2014).

\subsection{Dynamic equation}

The full dynamics equation of the lower limb was written. In contrast with the classical approach, the dynamics equation of the whole kinematic chain was used, introducing the musculo-tendon forces and the Lagrange multipliers (Dumas, Moissenet, Gasparutto, \& Chèze, 2012; Moissenet, Chèze, \& Dumas, 2012):

$$
\mathbf{G} \ddot{\mathbf{Q}}+\mathbf{K}^{T} \lambda=\mathbf{R}+\mathbf{P}+\mathbf{L f}
$$

where $\mathbf{G}$ is the generalized mass matrix, $\ddot{\mathbf{Q}}$ is the generalized accelerations vector, $\mathbf{K}^{T}$ is the Jacobian matrix of both kinematic and rigid body constraints, $\lambda$ is the 
Lagrange multipliers vector, $\mathbf{R}$ is the generalized ground reaction, $\mathbf{P}$ is the generalized weight, $\mathbf{L}$ is the generalized muscular lever arms matrix and $\mathbf{f}$ is the musculo-tendon forces vector. Using this formulation, the Lagrange multipliers correspond straightforwardly to the joint contact, ligament and bone forces (Moissenet et al., 2012). This dynamic equation is used as a constraint when the musculo-tendon forces are estimated by a static optimisation (Moissenet et al., 2014).

In order to determine the individual musculo-tendon force $f^{j}$ contributions to accelerations (i.e., $\ddot{\mathbf{Q}}^{f^{j}}$ ) and to ground reaction (i.e., $\mathbf{R}^{f^{j}}$ ), a parameter reduction was applied to equation (1) in order to cancel the Lagrange multipliers (Garcia de Jalon \& Bayo, 1994; Moissenet et al., 2012):

$$
\mathbf{Z}_{\mathbf{K}}^{T} \mathbf{G} \ddot{\mathbf{Q}}+\underbrace{\mathbf{Z}_{\mathbf{K}}^{T} \mathbf{K}^{T} \lambda}_{\mathbf{0}}=\mathbf{Z}_{\mathbf{K}}^{T} \mathbf{R}+\mathbf{Z}_{\mathbf{K}}^{T} \mathbf{P}+\mathbf{Z}_{\mathbf{K}}^{T} \mathbf{L f}
$$

where $\mathbf{Z}_{\mathbf{K}}$ is the orthogonal basis of the null space of $\mathbf{K}$. $\mathbf{R}^{f^{j}}$ and $\ddot{\mathbf{Q}}^{f^{j}}$ can then be computed in isolation (i.e., with $\mathbf{P}=\mathbf{0}$ and all $f^{j}=0$ except one) by a pseudo-inverse method (Lin et al., 2011).

Similarly, in order to determine the individual musculo-tendon forces contributions to joint contact, ligament and bone forces, a partial parameter reduction was then applied on equation (1) in order to cancel a selection of Lagrange multipliers (Moissenet et al., 2014):

$$
\begin{aligned}
\mathbf{Z}_{\mathbf{K}_{2}}^{T} \mathbf{G} \ddot{\mathbf{Q}}+\mathbf{Z}_{\mathbf{K}_{2}}^{T} \mathbf{K}_{1}^{T} \lambda_{1}+\underbrace{\mathbf{Z}_{\mathbf{K}_{2}}^{T} \mathbf{K}_{2}^{T} \lambda_{2}}_{\mathbf{0}} & =\mathbf{Z}_{\mathbf{K}_{2}}^{T} \mathbf{R} \\
& +\mathbf{Z}_{\mathbf{K}_{2}}^{T} \mathbf{P}+\mathbf{Z}_{\mathbf{K}_{2}}^{T} \mathbf{L f}
\end{aligned}
$$

where $\lambda_{1}$ are a subset of the Lagrange multipliers representing only the joint contact forces, ligament forces and axial bone forces (Moissenet et al., 2014), $\lambda_{2}$ are all the other ones, $\mathbf{K}_{1}$ and $\mathbf{K}_{2}$ are the associated Jacobian matrices and $\mathbf{Z}_{\mathbf{K}_{2}}$ is the orthogonal basis of the null space of $\mathbf{K}_{2}$. Again, $\lambda_{1}^{f^{j}}$ can be then computed in isolation (i.e., with $\mathbf{P}=\mathbf{0}$ and all $f^{j}=0$ except one) by a pseudo-inverse method (Lin et al., 2011):

$\lambda_{1}^{f^{j}}=\left[\mathbf{Z}_{\mathbf{K}_{2}}^{T} \mathbf{K}_{1}^{T}\right]^{\dagger}\left(-\mathbf{Z}_{\mathbf{K}_{2}}^{T} \mathbf{G} \ddot{\mathbf{Q}}^{f^{j}}+\mathbf{Z}_{\mathbf{K}_{2}}^{T} \mathbf{R}^{f^{j}}+\mathbf{Z}_{\mathbf{K}_{2}}^{T} \mathbf{L}\left[\begin{array}{c}\vdots \\ 0 \\ \vdots \\ f^{j} \\ \vdots \\ 0 \\ \vdots\end{array}\right]\right)$.

\subsection{Application to normal gait analysis}

The previously described computational framework was finally applied to a normal gait cycle. The selected cycle was extracted from the dataset provided for the first "Grand Challenge Competition to Predict in Vivo Knee Loads" (Fregly et al., 2012) and was recorded on a subject (male $/ 166 \mathrm{~cm} / 64.6 \mathrm{~kg}$ ) having an instrumented knee prosthesis measuring both medial and lateral tibiofemoral contact forces. A full description of the dataset is provided by Fregly et al. (2012).

First, the musculo-tendon forces were computed by static optimisation and the validity of the results was evaluated through a quantitative comparison between estimated tibiofemoral medial and lateral contact forces and prosthesis measurements by expressing the root mean square error (i.e., RMSE) between the data. Second, the individual musculo-tendon forces contributions to ground reaction $\mathbf{R}^{f^{j}}$ (from which the ground reaction forces and moments, $\mathbf{F}_{0}^{R, f^{j}}, \mathbf{M}_{0}^{R, f^{j}}$, can be deduced (Dumas \& Chèze, 2007)) and to contact forces, ligament forces and axial bone forces (i.e., $\lambda_{1}^{f^{j}}$ ) were computed and a qualitative comparison between estimations and literature data was performed. Detailed literature data were available for the contributions of musculo-tendon forces to both vertical ground reaction force (Lin et al., 2011) and total tibiofemoral contact force (Sritharan et al., 2012) during the stance phase. Third, the contribution of musculotendon forces to axial compression force of the femur was computed.

\section{Results}

The comparison between the estimated and the measured tibiofemoral medial and lateral contact forces is given in Figure 1. Both medial and lateral tibiofemoral contact forces are well replicated at the first peak of force, while magnitude and phase errors are observed at the second peak of force. Anyway, the RMSE values remain low (i.e., medial $\mathrm{RMSE}=0.37 \mathrm{BW}$, lateral $\mathrm{RMSE}=0.25 \mathrm{BW}$ ).

The comparison between the contributions of a set of musculo-tendon forces to the vertical ground reaction force estimated through the proposed framework and published by Lin et al. (2011) is given in Figure 2. At the first peak of force, the contribution of the gluteus medius is similar in both studies while the present estimations suggest a greater contribution of the vastii and a smaller contribution of the gluteus maximus. At the second peak of force, the sharing between soleus and gastrocnemii is similar in both studies, but the present estimations suggest an earlier contribution of the soleus.

The comparison between the contribution of a set of musculo-tendon forces to the total tibiofemoral contact force estimated through the proposed framework and published by Sritharan et al. (2012) is given in Figure 3. At the early stance phase, a similar contribution of hamstrings is obtained in both studies. At the first peak of force, both vastii and rectus femoris contribute to the total tibiofemoral contact force with a higher contribution of the rectus femoris in the present estimations. At 


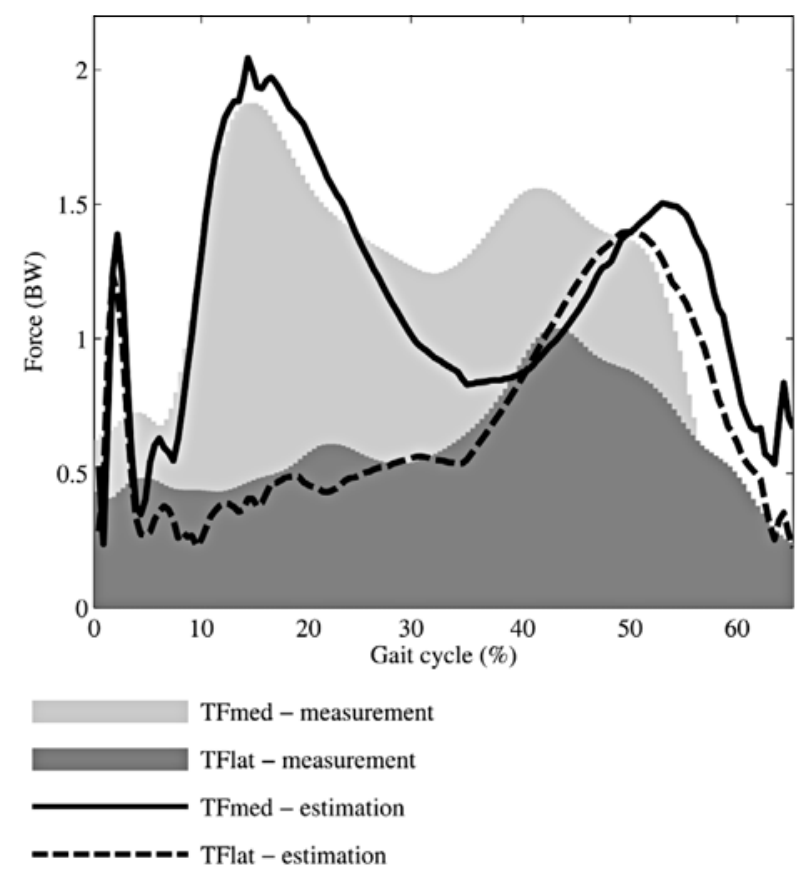

Fig. 1. Comparison between the estimated and the measured tibiofemoral medial and lateral contact forces (i.e., TFmed tibiofemoral medial contact, TFlat - tibiofemoral lateral contact). Forces are given in body weight (BW) during the gait cycle expressed in percentages $(\%)$. Only the stance phase is interpreted (i.e., between $0 \%$ and $65 \%$ of the gait cycle).

the second peak of force, gastrocnemii and biceps femoris short head contribute to the total tibiofemoral contact force in a similar way in both studies. Finally, at the end of stance phase, the contribution of the rectus femoris is again significant in both studies but appears later in the present estimations.

The estimation of the contributions of a set of musculo-tendon forces to the axial compression force of the femur is given in Figure 4. While most of the muscles crossing the hip and knee joints contribute to the axial compression force of the femur, it must be noticed that the main contributors at the first and second peak of force are respectively the rectus femoris and the sartorius, that are both biarticular muscles.

\section{Discussion}

Study of the contribution of individual musculo-tendon forces may allow a better comprehension of the underlying mechanisms during gait (Pandy \& Andriacchi, 2010) and may provide insight about either pathologic gait patterns (Higginson et al., 2006; Steele et al., 2013) or the progression of joint disorders such as osteoarthritis (Herzog et al., 2003; Sasaki \& Neptune, 2010; Shelburne et al., 2006). While the contribution of musculo-tendon forces to ground reaction forces and mass acceleration is well described in the literature, the contribution to osteo-articular forces (i.e., joint contact, ligament and bone forces) remains rarely explored and, to the authors' knowledge, no study has analysed the contribution of individual musculo-tendon forces to patellofemoral forces, to ligament forces or to bone forces. The aim of this study was thus to develop a method allowing the investigation of the contributions of individual musculotendon forces to all the forces of the osteo-articular system. This method is based on the pseudo-inverse proposed by Lin et al. (2011) but applied to a specific 3D lower limb musculoskeletal model (Moissenet et al., 2014). Pseudo-inverse is an interesting method as far as computational cost is concerned. Indeed, Lin et al. (2011) have demonstrated similar results in terms of temporal patterns when estimating the muscular contribution to the vertical ground reaction force by their pseudo-inverse or a forward dynamics method (Anderson \& Pandy, 2003). However, the amplitudes of the contribution of each muscle were slightly different, probably due to differences in kinematics and ground reactions (i.e., simulated vs. recorded gait data). The model used in the present study includes numerous Lagrange multipliers standing for the osteo-articular forces and a parameter reduction allows isolating the ground reaction forces and segment accelerations or the contact forces, ligament forces and axial bone forces that can be advantageously used in the pseudoinverse method. This study aims extending the literature by providing the contribution of musculo-tendon forces to the axial compression force of the femur during normal gait.

The 3D lower limb musculoskeletal model provided reliable tibiofemoral contact forces and the adapted pseudoinverse method was able to replicate well the literature for the contribution of musculo-tendon forces to both the vertical ground reaction force and the total tibiofemoral contact force. Slight differences are however observed and can be attributed to the differences between the models (e.g., kinematic models (Dumas et al., 2012), muscular geometry (Carbone, van der Krogt, Koopman, \& Verdonschot, 2012), objective function used in the static optimisation (Moissenet, Chèze, \& Dumas, 2014)) and, to some extent, to the formulation of the pseudo-inverse method. The investigation of the contribution of musculo-tendon forces to the axial compression force of the femur suggested, as expected, that most of the muscles crossing hip and knee joints contribute to this compression. More interestingly, the major contributors (i.e., rectus femoris and sartorius) are both biarticular muscles. This observation suggests that biarticular muscles, during their contraction, lead to high stresses in the bony structures.

Of course, the results obtained through the use of a generic musculoskeletal model must be interpreted carefully. While medical imaging can allow adjusting some parameters of the model, a daily clinical use of such a model remains complicated. However, even generic, a musculoskeletal model is an attractive tool to understand the musculoskeletal structures functions, interactions and disorders. Moreover, the comparison between estimated and 

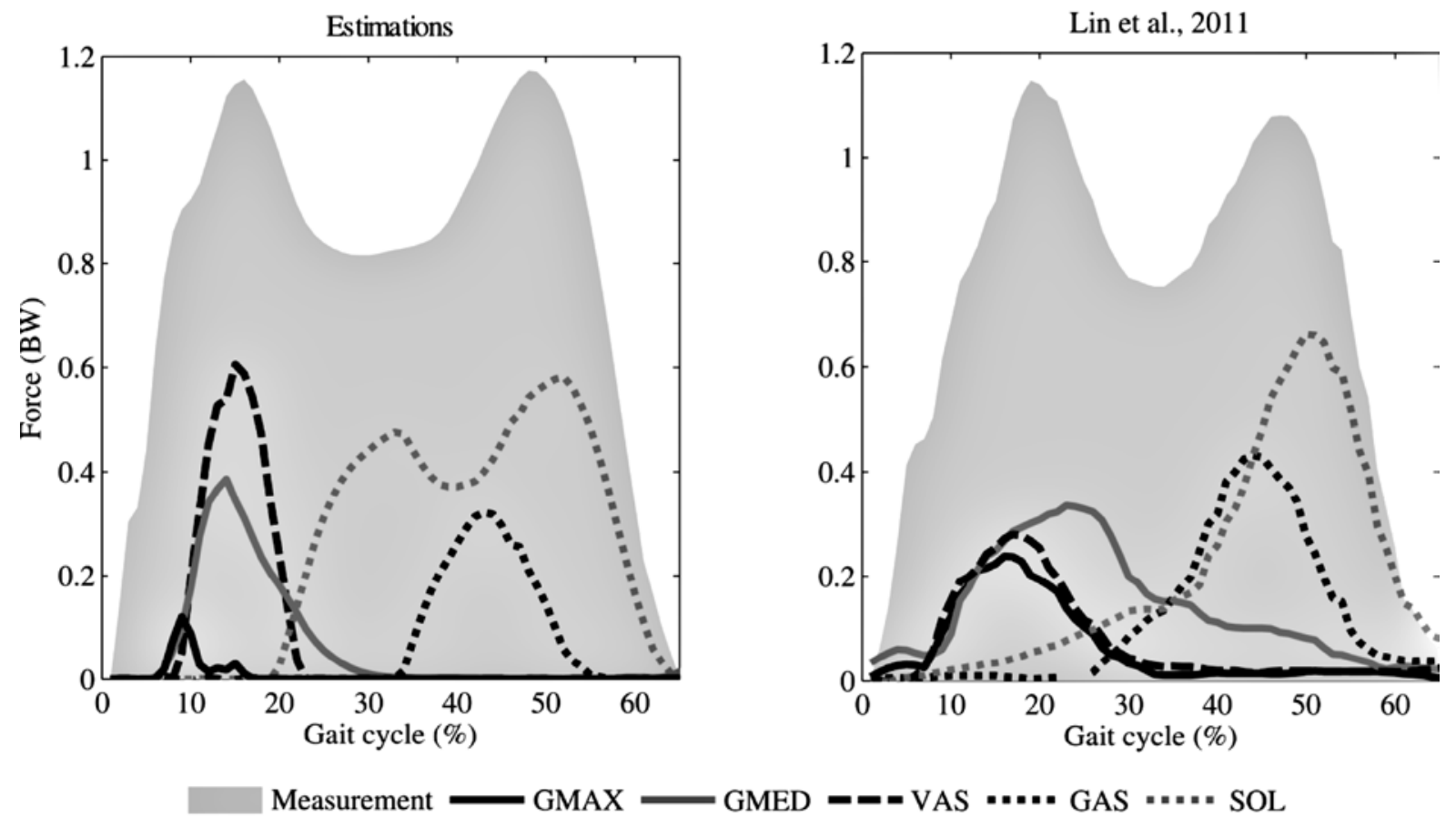

Fig. 2. Comparison between the contributions of a set of musculo-tendon forces (i.e., GMAX - Gluteus maximus, GMED Gluteus medius, VAS - Vastii, GAS - Gastrocnemii, SOL - Soleus) to the vertical ground reaction force (i.e., Measurement) estimated through the proposed framework (left side) and published by Lin et al. (Lin et al., 2011) (right side). Forces are given in body weight (BW) during the gait cycle expressed in percentages (\%). Only the stance phase is interpreted (i.e., between $0 \%$ and $65 \%$ of the gait cycle).
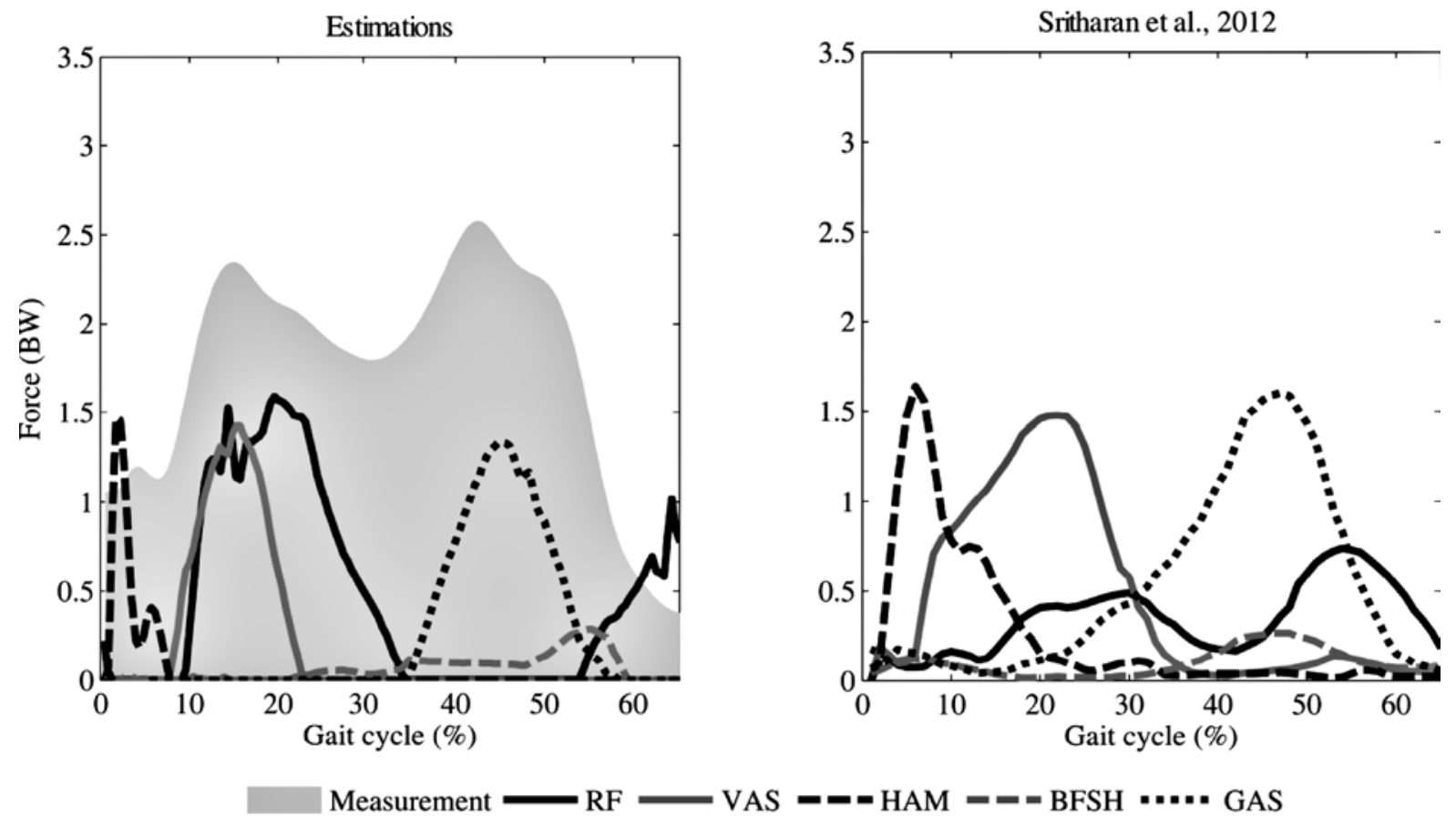

Fig. 3. Comparison between the contributions of a set of musculo-tendon forces (i.e., RF - Rectus femoris, VAS - Vastii, HAM Hamstrings, BFSH - Biceps femoris short head, GAS - Gastrocnemii) to the total tibiofemoral contact force (i.e., Measurement with instrumented prosthesis) estimated through the proposed framework (left side) and published by Sritharan et al. (2012) (right side). Forces are given in body weight (BW) during the gait cycle expressed in percentages (\%). Only the stance phase is interpreted (i.e., between $0 \%$ and $65 \%$ of the gait cycle). 


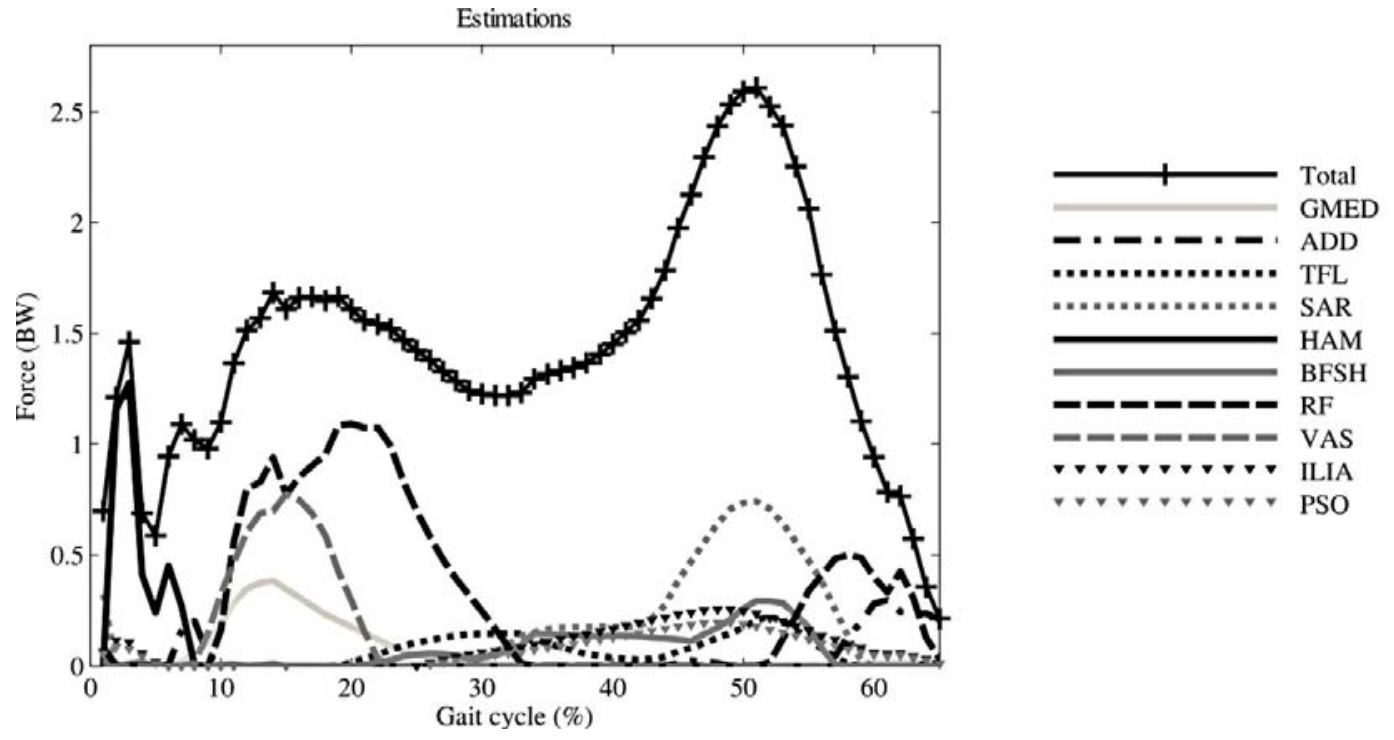

Fig. 4. Contributions of a set of musculo-tendon forces (i.e., GMED - Gluteus medius, ADD - Adductors, TFL - Tensor fascia lata, SAR - Sartorius, HAM - Hamstrings, BFSH - Biceps femoris short head, RF - Rectus femoris, VAS - Vastii, ILIA Iliacus, PSO - Psoas) to the axial compression force of the femur (i.e., Total). Forces are given in body weight (BW) during the gait cycle expressed in percentages (\%). Only the stance phase is interpreted (i.e., between $0 \%$ and $65 \%$ of the gait cycle).

measured tibiofemoral medial and lateral contact forces suggests that the present results reflect quite well the measurements and could be close to the real forces.

To conclude, the pseudo-inverse method adapted to the 3D lower limb musculoskeletal model presented in this study proposes an interesting computational framework for investigating interactions between the different musculoskeletal structures through an inverse dynamics approach. This study presents new results by introducing the contribution of musculo-tendon forces to the axial compression force of the femur during normal gait. Further computations could now be considered to investigate the contribution of these forces to other structures and during other motor tasks.

\section{Bibliography}

Anderson, F.C., \& Pandy, M.G. (2003). Individual muscle contributions to support in normal walking. Gait 85 Posture, 17 (2), 159-169.

Arnold, A.S., Schwartz, M.H., Thelen, D.G., \& Delp, S.L. (2007). Contributions of muscles to terminal-swing knee motions vary with walking speed. Journal of Biomechanics, 40 (16), 3660-3671.

Barrett, R.S., Besier, T.F., \& Lloyd, D.G. (2007). Individual muscle contributions to the swing phase of gait: An EMGbased forward dynamics modelling approach. Simulation Modelling Practice and Theory, 15 (9), 1146-1155.

Carbone, V., van der Krogt, M.M., Koopman, H.F.J.M., \& Verdonschot, N. (2012). Sensitivity of subject-specific models to errors in musculo-skeletal geometry. Journal of Biomechanics, 45 (14), 2476-2480.
Chèze, L., Moissenet, F., \& Dumas, R. (In press). State of the art and current limits of musculo-skeletal models for clinical applications. Movement $\&$ Sport Sciences - Science \& Motricité, doi: $10.1051 / \mathrm{sm} / 2012026$.

Collins, J.J., \& O'Connor, J.J. (1991). Muscle-ligament interactions at the knee during walking. Proceedings of the Institution of Mechanical Engineers. Part H, Journal of Engineering in Medicine, 205 (1), 11-18.

Correa, T.A., Crossley, K.M., Kim, H.J., \& Pandy, M.G. (2010). Contributions of individual muscles to hip joint contact force in normal walking. Journal of Biomechanics, 43 (8), 1618-1622.

Correa, T.A., \& Pandy, M.G. (2013). On the potential of lower limb muscles to accelerate the body's centre of mass during walking. Computer Methods in Biomechanics and Biomedical Engineering, 16 (9), 1013-1021.

Delp, S.L., Loan, J.P., Hoy, M.G., Zajac, F.E., Topp, E.L., \& Rosen, J.M. (1990). An interactive graphics-based model of the lower extremity to study orthopaedic surgical procedures. IEEE Transactions on Bio-Medical Engineering, 37 (8), 757-767.

Di Gregorio, R., Parenti-Castelli, V., O’Connor, J.J., \& Leardini, A. (2007). Mathematical models of passive motion at the human ankle joint by equivalent spatial parallel mechanisms. Medical \& Biological Engineering $\&$ Computing, 45 (3), 305-313.

Dumas, R., \& Chèze, L. (2007). 3D inverse dynamics in non-orthonormal segment coordinate system. Medical \& Biological Engineering \& Computing, 45 (3), 315-322.

Dumas, R., Moissenet, F., Gasparutto, X., \& Chèze, L. (2012). Influence of joint models on lower-limb musculo-tendon forces and three-dimensional joint reaction forces during 
gait. Proceedings of the Institution of Mechanical Engineers. Part H, Journal of Engineering in Medicine, 226 (2), 146-160.

Duprey, S., Cheze, L., \& Dumas, R. (2010). Influence of joint constraints on lower limb kinematics estimation from skin markers using global optimization. Journal of Biomechanics, 43 (14), 2858-2862.

Erdemir, A., McLean, S., Herzog, W., \& van den Bogert, A.J. (2007). Model-based estimation of muscle forces exerted during movements. Clinical Biomechanics (Bristol, Avon), 22 (2), 131-154.

Feikes, J.D., O'Connor, J.J., \& Zavatsky, A.B. (2003). A constraint-based approach to modelling the mobility of the human knee joint. Journal of Biomechanics, 36( 1), $125-129$.

Fox, M.D., \& Delp, S.L. (2010). Contributions of muscles and passive dynamics to swing initiation over a range of walking speeds. Journal of Biomechanics, 43(8), 1450-1455.

Fregly, B.J., Besier, T.F., Lloyd, D.G., Delp, S.L., Banks, S.A., Pandy, M.G., \& D'Lima, D.D. (2012). Grand challenge competition to predict in vivo knee loads. Journal of Orthopaedic Research 30 (4), 503-513.

Fregly, B.J., Lin, Y., Walter, J.P., Pandy, M.G., Banks, S.A., \& D'Lima, D.D. (2009). Muscle and contact contributions to inverse dynamic knee loads during gait. In Proceedings of the ASME 2009 Summer Bioengineering Conference (pp. SBC2009-206558).

Garcia de Jalon, J., \& Bayo, E. (1994). Kinematic and dynamic simulation of multibody systems. The real-time challenge. Springer-Verlag, New-York.

Goldberg, S.R., \& Kepple, T.M. (2009). Muscle-induced accelerations at maximum activation to assess individual muscle capacity during movement. Journal of Biomechanics, $42(7), 952-955$.

Hamner, S.R., \& Delp, S.L. (2013). Muscle contributions to fore-aft and vertical body mass center accelerations over a range of running speeds. Journal of Biomechanics, 46 (4), $780-787$.

Herzog, W., Longino, D., \& Clark, A. (2003). The role of muscles in joint adaptation and degeneration. Langenbeck's Archives of Surgery/Deutsche Gesellschaft Für Chirurgie, 388 (5), 305-315.

Higginson, J.S., Zajac, F.E., Neptune, R.R., Kautz, S.A., \& Delp, S.L. (2006). Muscle contributions to support during gait in an individual with post-stroke hemiparesis. Journal of Biomechanics, 39 (10), 1769-1777.

Jansen, K., De Groote, F., Duysens, J., \& Jonkers, I. (2013). Muscle contributions to center of mass acceleration adapt to asymmetric walking in healthy subjects. Gait and Posture, 38 (4), 739-744.

Kim, H.J., Fernandez, J.W., Akbarshahi, M., Walter, J.P., Fregly, B.J., \& Pandy, M.G. (2009). Évaluation of predicted knee-joint muscle forces during gait using an instrumented knee implant. Journal of Orthopaedic Research, 27 (10), 1326-1331.

Klemetti, R., Steele, K.M., Moilanen, P., Avela, J., \& Timonen, J. (2014). Contributions of individual muscles to the sagittal- and frontal-plane angular accelerations of the trunk in walking. Journal of Biomechanics, 47 (10), 2263-2268.

Lin, Y.C., Kim, H.J., \& Pandy, M.G. (2011). A computationally efficient method for assessing muscle function during human locomotion. International Journal for Numerical Methos in Biomedical Engineering, 27 (3), 436-449.

Liu, M.Q., Anderson, F.C., Schwartz, M.H., \& Delp, S.L. (2008). Muscle contributions to support and progression over a range of walking speeds. Journal of Biomechanics, 41 (15), 3243-3252.

Moissenet, F., Chèze, L., \& Dumas, R. (2012). Anatomical kinematic constraints: consequences on musculo-tendon forces and joint reactions. Multibody System Dynamics, $28(1-2), 125-141$.

Moissenet, F., Chèze, L., \& Dumas, R. (2014). A 3D lower limb musculoskeletal model for simultaneous estimation of musculo-tendon, joint contact, ligament and bone forces during gait. Journal of Biomechanics, 47 (1), 50-58.

Neptune, R. R., Zajac, F. E., \& Kautz, S. A. (2004). Muscle force redistributes segmental power for body progression during walking. Gait $\&$ Posture, 19 (2), 194-205.

Pandy, M.G., \& Andriacchi, T.P. (2010). Muscle and joint function in human locomotion. Annual Review of Biomedical Engineering, 12, 401-433.

Sancisi, N., \& Parenti-Castelli, V. (2011). A new kinematic model of the passive motion of the knee inclusive of the patella. Journal of Mechanisms and Robotics, 3 (4), 041003.

Sasaki, K., \& Neptune, R.R. (2010). Individual muscle contributions to the axial knee joint contact force during normal walking. Journal of Biomechanics, 43 (14), 2780-2784.

Shelburne, K.B., Torry, M.R., \& Pandy, M.G. (2006). Contributions of muscles, ligaments, and the groundreaction force to tibiofemoral joint loading during normal gait. Journal of Orthopaedic Research, 24 (10), 1983-1990.

Sritharan, P., Lin, Y.-C., \& Pandy, M.G. (2012). Muscles that do not cross the knee contribute to the knee adduction moment and tibiofemoral compartment loading during gait. Journal of Orthopaedic Research, 30 (10), 1586-1595.

Steele, K.M., Seth, A., Hicks, J.L., Schwartz, M.H., \& Delp, S.L. (2013). Muscle contributions to vertical and fore-aft accelerations are altered in subjects with crouch gait. Gait 8 Posture, 38 (1), 86-91.

Winby, C.R., Lloyd, D.G., Besier, T.F., \& Kirk, T.B. (2009). Muscle and external load contribution to knee joint contact loads during normal gait. Journal of Biomechanics, 42 (14), 2294-2300. 